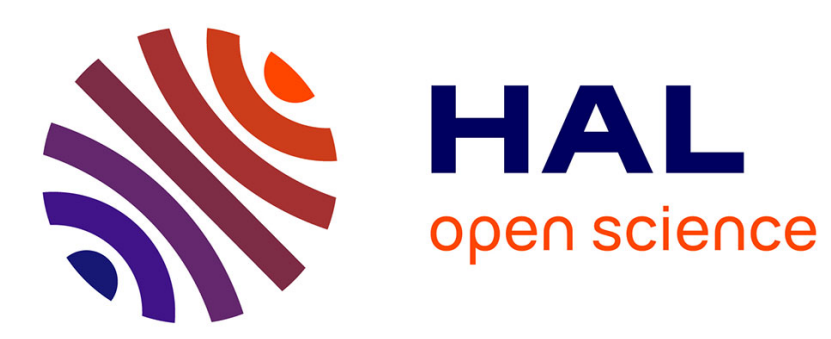

\title{
Do the coach and athlete have the same "picture" of the situation? Distributed Situation Awareness in an elite sport context
}

\author{
Anne-Claire Macquet, Neville A. Stanton
}

\section{- To cite this version:}

Anne-Claire Macquet, Neville A. Stanton. Do the coach and athlete have the same "picture" of the situation? Distributed Situation Awareness in an elite sport context. Applied Ergonomics, 2014, 45 (3), pp.724 - 733. 10.1016/j.apergo.2013.09.014 . hal-01765878

\section{HAL Id: hal-01765878 \\ https: / hal-insep.archives-ouvertes.fr/hal-01765878}

Submitted on 17 Apr 2018

HAL is a multi-disciplinary open access archive for the deposit and dissemination of scientific research documents, whether they are published or not. The documents may come from teaching and research institutions in France or abroad, or from public or private research centers.
L'archive ouverte pluridisciplinaire HAL, est destinée au dépôt et à la diffusion de documents scientifiques de niveau recherche, publiés ou non, émanant des établissements d'enseignement et de recherche français ou étrangers, des laboratoires publics ou privés. 


\title{
Do the coach and athlete have the same «picture» of the situation? Distributed Situation Awareness in an elite sport context
}

\author{
Anne-Claire Macquet $^{a, *}$, Neville A. Stanton ${ }^{b}$ \\ ${ }^{a}$ French National Institute of Sport, Expertise and Performance (INSEP), Paris, France \\ ${ }^{\mathrm{b}}$ Southampton University, UK
}

a $r$ t c l e i n f o

\section{Keywords:}

Collaborative system

Joint cognitive system

Expertise in sports

\begin{abstract}
$\mathrm{a} b \mathrm{~s}$ t $\mathrm{r}$ a c t
Athletes and their coach interpret the training situations differently and this can have important im plications for the development of an elite athlete's performance. It is argued that, from a schematheoretic perspective, the difference in these interpretations needs to be better understood. A postperformance, self-confrontation, interview was conducted with a number of athletes and their coaches. The interviews revealed differences between the athlete and their coach in the information they are aware of. In comparison with athletes, coaches more frequently compared the phenotype with genotype schemata rather than just describing the phenotype schemata. Results suggest SA information elements showed some common ground but also revealed some important differences between the athlete and coach. The awareness was directed externally towards the environment and internally, towards the individual, depending on his/her role. The investigation showed that the schemata used to 'frame' the information elements were different, but compatible, between athlete and coach.
\end{abstract}

\section{Introduction}

In elite sports, it is important to know what information is understood by athletes and coaches, in order to help athletes improve their performance (e.g., Lorimer and Jowett, 2011; Macquet, 2013). The coach and athlete may interpret the situation in which the athlete is involved and athlete's behavior quite differently. They both possess knowledge about the best way to achieve positive outcomes in relation to biomechanics, sport rules, athlete's competencies and tendencies, contextual information such as the influence of the wind on performance. There are likely differences in these underlying knowledge structures which will be revealed in the situation awareness of both athlete and coach.

According to the schema theorists (e.g., Bartlet, 1932; Neisser, 1976; Norman, 1981; Piaget, 1926; Plant and Stanton, 2013), this knowledge is used at a specific time and situation to carry out and interpret athlete's behavior and situation. Interpretation allows the coach and athlete to understand what went well or badly, and why (e.g., Hanton et al., 2009). Due to their bounded rationality (Simon,

\footnotetext{
* Corresponding author. Research Department, Laboratory of Sport, Expertise and Performance (SEP), French National Institute of Sport, Expertise and Performance (INSEP), 11 avenue du Tremblay, 75012 Paris, France. Tel.: + 33141744 873; fax: p33 141744535 .

E-mail address: anne-claire.macquet@insep.fr (A.-C. Macquet).
}

1996), they cannot possibly understand all the elements of the situation. They rather interpret the "triggers" of the situation (Norman, 1981). In elite sports, to improve performance, it seems important to know whether their "triggers" are similar or different, and whether "triggers" are understood at the same way.

To carry out and interpret a behavior, the individuals use schemata which are stored in memory (e.g., Bartlet, 1932; Neisser, 1976; Norman, 1981; Piaget, 1926; Plant and Stanton, 2013). Schemata are continually reorganized and completed regarding the interactions of the individual's with his/her environment in which the behavior is carried out. Anderson (1977) stressed five main defining features of schemata: (a) schemata are mapped meaningfully in specific way; (b) pertain to other macro-schemata and contain subschemata; (c) are modified regarding information perceived; (d) are restructured in relation to incoming information; and (e) are gestalt mental representations. Stanton et al. (2009) distinguish between two types of schemata: the genotype and phenotype. The genotype schemata refer to "the wider systemic factors that influence the development of individual cognitive phenomena and behavior" (p. 46). In sport context, genotype schemata are concerned with the "ideal" and expected behavior/skill as well as the athlete's competencies and tendencies as athlete performs a task. They refer to his/her own schema-based theory of how to complete tasks efficiently. The phenotype is concerned with available information within the system; it is the blend of genotype, plus the 
environment, random factors to produce and interpret the behavior and situation; it is the "local individual-specific manifestation of cognition and behavior" (p. 46). Schema theory is used by psychologists to describe everyday activities, such as learning (Wood, 1998), sense-making and decision-making (e.g., Klein et al., 2010; Macquet and Kragba, 2014), situation awareness (Stanton et al., 2006) and human error (Plant and Stanton, 2013).

According to Neisser's (1976) theory of perceptioneaction cycle based on the work of James and Eleanor Gibson, the interaction between the operator and his/her environment is cyclical rather than linear. Operator is guided by the active knowledge structures, namely the schemata, to perceive and interpret information. In return, information contributes to change these structures and consequently change the direction of perception and interpretation. Schemata determine what the operator is able to perceive and whether perceived information fits with the schemata. Neisser's (1976) perceptioneaction cycle theory associated to the schema theory account both for how the environment and cognition "guides" one's perception and interpretation of the environment and situation.

Stanton et al. (2009) have mapped the schema theory with the perceptioneaction cycle theory onto the concept of Situation Awareness (SA). SA allows explain how humans interact with their environment. In the literature, two main models are distinguished to describe SA: Endsley's (1995) three-levels model, which is the most popular, and Smith's and Hancock's (1995) model based on Neisser's perceptioneaction cycle theory. These models refer to different definition of SA. For Endsley (1995), SA represents awareness of "what's going on" and "what might happen" when operators complete tasks in a complex system, and how awareness develops and is maintained. SA is a cognitive product which results from a separate process called situation assessment. For Smith and Hancock (1994), SA is the "picture" of the situation to which it refers. "SA is all about having the right stuff" (p. 61). It requires adherence to the task goals and performance criteria, which implies that SA is goal-driven behavior. SA is the process of adaptation to task constraints. In this way, SA is directed externally towards the environment. It is responsible for conscious and dynamic reflection on the situation (Bedny and Meister, 1999). SA is at the same time a product and a process. Poor SA makes performance improvement difficult, because individuals do not know what went well and what went badly or identify the wrong aspects of performance that went well or badly.

According to what was said above, Smith's and Hancock's definition of SA, based on the perceptioneaction cycle approach seems the most suitable to study team SA in complex environment. It allows to understand how the environment constraints the operator' SA as well as what the "picture" of the situation is. It also proposed that people possess personalized "genotype" and "phenotypes" schemata that are triggered by the relevant task constraints and required task performance. As Neisser puts it, "schemata are developed by experience; everyone's experiences are different; since every person's perceptual history is unique we should all have unique cognitive structures" (Neisser, 1976, p. 187). This means that we should expect the athlete and coach to have different awareness of the same situation, one from the point of view of experiencing the situation first hand and the other from the point of view of observing the athlete. The coach will also have many more years experience to draw upon as well as observations of many athletes' performance. They also may have had the experience of being an athlete themselves before becoming a coach.

Although the SA concept is applicable to a sports context, it has received little attention (James and Patrick, 2004). To our knowledge, only one study has focused on athlete and coach SA while involved in training sessions and competition (Macquet, 2013).
Macquet has developed a method for analyzing coach's and athlete's SA in a sports context. Other studies on SA in sports centered on athletes' SA and decision-making (e.g., Johnson and Raab, 2003; Macquet, 2009; Macquet et al., 2012; Macquet and Fleurance, 2007).

The coach and athlete work together in a specific environment. They belong to a collaborative system and team: a team contains at least two persons aiming the same main goals which they pursue collaboratively and can succeed or fail as a whole (e.g., Annett and Stanton, 2000; Klein et al., 2010). Salas et al. (1995) stressed that team SA is more than the combination of individual team member's SA. In collective activities, individuals need to perceive, interpret and anticipate SA elements in relation to their role within the team and are required to share them (e.g., Salas et al., 1995).

The concept of shared SA is ambiguous: do the team members accessing the same information understand the situation in exactly the same way whatever their role within the team? To respond to this question, Stanton et al. (2006) have recently developed the Distributed Situation Awareness (DSA) model. They have used Hutchins's (1995) theory on distributed cognition and Hollnagel's (1993) work about cognitive system engineering. Hutchins and Hollnagel stress that, rather than being solely in the heads of individuals SA is also embedded in the context. Context provides useful information on "what's going on", and arises from the interactions between individuals and between the individual and the situation. It is distributed across team members and artifacts. Even when team members have access to the same information, they make different connections between the information or link it in different ways in relation to their own skills, experiences, role and objectives in order to understand the situation. "Awareness" is the whole combined experience. The connections people make with data to build a frame (i.e., schema) are different. So, whilst they may share data, the connections of data-in-the-frame (i.e., schema) are different.

Compatible SA refers to the phenomenon that allows the system to be a cognitive joint system (e.g., Stanton et al., 2006, 2009). Studying the compatibility between athlete's and coach's SA would allow insights into their SA at each point in time and determine whether together the athlete and coach have a more complete "picture" of the situation than either possesses alone. It also allows explain whether genotype and phenotype schemata are activated in the course of action.

Moreover, information exchanges occurring between people are called transactions (e.g., Stanton et al., 2010). A transaction is an exchange of awareness rather than a sharing. These concepts of compatibility and transaction highlight the distributed nature of cognition and SA in comparison to the idea of shared SA in collaborative systems. In the DSA model, the cognitive system is viewed as a whole, using the information available to people during interactions.

It is argued by Salmon et al. (2010b) that a similar model could be used to study collaborative systems, such as the coach-athlete system, and sport teams. DSA model is underpinned by the schema theory (e.g., Bartlet, 1932; Neisser, 1976; Norman, 1981; Piaget, 1926; Plant and Stanton, 2013), perceptioneaction cycle approach (Neisser, 1976), distributed cognition theory (Hutchins, 1995), and cognitive system engineering (Hollnagel, 1998). The use of schema theory and perceptioneaction cycle approach gives the DSA model a cyclical and parallel process of situation perception and interpretation which serves to explain how and what the coach and athlete focus on, perceive and interpret the situation and possible causes of athlete's behavior (they have pre-existing schemata). The use of perceptioneaction cycle approach, distributed cognition theory and cognitive system engineering allows focus on the system level (i.e., the coach and athlete considered as a whole) 
and coordination between the coach and athlete, and between them and their environment. DSA model seems well suited to explain coach's and athlete's SA in different practice contexts.

To model DSA in collaborative systems, Stanton et al. (2006) developed a method centered around the construction of propositional networks. Such networks link elements of information to account for information underlying the system awareness (i.e., data in the frame as proposed by Klein et al., 2010). They highlight the relationships between elements of information and the way each part of the system uses each element of information for each type of task to be performed. Although these networks are very useful for modeling system awareness and information elements underlying SA, their construction can be highly time-consuming, requires very skilled analysts, and is difficult to present within articles (Salmon et al., 2010a). Moreover, it does not provide insights into the macro information elements of the system nor their frequency for each individual within the system. These insights could be used to improve intervention during training sessions and competitions. To avoid these limitations, we did not use this method and instead chose Macquet's (2013) method. Macquet's method allowed compare the consistency of coach's and athlete's SA during competitions and training sessions to identify compatible information elements. This method was developed to show the content of compatible information elements between one coach and three athletes and modes of compatibility of information elements (i.e., no compatibility, compatibility, mutual compatibility). We supplemented this method to achieve the goals of the present study.

The present study aimed to compare the consistency of six athletes' and three coaches' SA at each point in time during training sessions and competitions. SA was studied from the information elements it contained. These information elements pertained to the coach's and athlete's schemata which were activated at each point in time and referred to the phenotype and genotype schemata. These schemata and their specific content gave insight about the "picture" of the situation and athlete's behavior to which they referred. More specifically, the present study aimed to categorize: (a) the content of information elements held by each athlete and his/her coach at each point in time they (b) the content of information elements which were compatible between the athlete and his/her coach; and (c) the nature of information elements held by each athlete and his/her coach, namely the phenotypes and genotypes schemata. The content and nature of information elements pertaining to SA gave insight into the sense the participants made of situation and their projection into the future (i.e., what to focus on in the following action, complete a specific behavior to avoid negative outcomes, such as getting a drink to avoid cramps). The compatibility between the information elements at each point in time showed they understood the situation at the same way.

The present study was conducted for hammer throwing and rowing. These sports are technical sports, in which athletes need to demonstrate efficient technique to perform well. Hammer throwing consists of a set of discrete actions that are combined to form an overall action (i.e., a throw). Each set is independent from the previous and following ones. Rowing consists of a series of actions which follow one another in cycles; actions are interdependent and of long duration.

\section{Method}

\subsection{Participants}

Six elite athletes (two female and two male hammer throwers, and one female and one male rower) and three male coaches (one in hammer throwing and two in rowing) volunteered to participate. The criteria employed to select them included: (a) practicing their sport for more than 6 years; (b) being elite athlete; (c) working with their coach/athlete for several years; and (d) coaching in elite sport for more than 10 years. Athletes ranged in age from 20 to 31 years ( $M=26.33$ years, $S D=4.36$ years $)$; they had been practicing their sport for an average of 10 years $(S D=3 y e a r s)$. Two of them also participated in the Olympic Games. Coaches ranged in age from 36 to 58 years $(M=46.33$ years, $S D=11$ years $)$; they had been coaching for an average of 23.66 years ( $S D=13.28$ years). Athletes had been working with their coach for an average of 7.5 years $(S D=3.27$ years $)$. No other athletes and coaches who fulfilled all these requirements were available to participate to recorded training sessions and competition, and self-confrontation interviews. Such studies have often involved very few participants because, by definition, only a few individuals become expert (e.g., Ericsson et al., 2004; Nieuwenhuys et al., 2008).

Participants were given pseudonyms to guaranty their confidentiality: HT1, HT2, HT3, HT4 (hammer throwers 1e4), and R1 and R2 (rowers 1 and 2). The study was approved by a local ethics committee.

\subsection{Data collection}

To better understand what happen in different practice contexts, Athletes' and coaches' SA was studied on three sessions pertaining to the main practice contexts in elite sport: (a) HT1, HT2, HT3, and R1 participated in a winter training session (WTS) that aimed to improve athletes' technique to prepare for competitions (e.g., Macquet, 2010); (b) HT1, HT2, HT3, and HT4 participated in an international competition to qualify for the European Championships; and (c) HT1, HT2, HT4, and R2 participated in a postcompetition training session (PCTS) that aimed to adjust training according to what had happened in competition (Macquet, 2010; R2's competition was the French Championship). In rowing, coaches cannot observe and communicate with their athletes during competitions, so they could not participate in the competition session.

Two types of qualitative data were collected: (a) video recording of athletes' behavior, and coaches' and athletes' communication during training sessions and competitions; and (b) verbalizations during post-training interviews (Macquet, 2013).

\subsubsection{Video recording of athletes' and coaches' behavior during training sessions and competitions}

Athletes' behavior, and coaches' and athletes' communication were recorded by a digital camera and an HF microphone worn by the coach. In hammer throwing, the camera was fixed behind the circle and the net for a wide angle, to record the thrower's behavior, hammer trajectory, and communication. In rowing, the camera was held by a researcher in the coach's boat to record the rower's behavior, rower's skiff, and coach-athlete communication. The videotapes were used to provide behavioral and contextual data but also to stimulate the parties to re-experience the training session and competition during the interview.

\subsubsection{Verbalizations during post-training interviews}

Verbalization data were collected during self-confrontation interviews conducted with each athlete and coach separately. For each interview, the video recording of the training session or competition was played and the participant was invited to describe and comment upon his activity during the course of action without a posteriori analysis, rationalization or justification. He/she could stop the video as he/she wanted and go back to comment on a specific event, thought, feeling, perception he/she had in the course of action. The interviewer used specific prompts to encourage the participant to describe his/her SA as it was experienced (i.e., what 
did you perceived at this point in time? What did you feel? What did you do or aimed to do? What did you think about? What did you say to you?). The full interviews were video-recorded in order to check correspondence between the comments and action that was being described (i.e., contextual features and behaviors during the training sessions and competitions). Interviews were conducted by the same person, who had already conducted selfconfrontation interviews of this type in previous studies (e.g., Macquet, 2013, 2009; Macquet et al., 2012). They took place immediately after the training session and competition or the day after, but before the following training session, depending on the availability of participants. 24 interviews were conducted and lasted between 30 and $99 \mathrm{~min}$ for athletes $(M=62 \mathrm{~min} ; S D=28 \mathrm{~min})$ and 26 and $97 \mathrm{~min}$ for coaches $(M=49 \mathrm{~min}$; $S D=21 \mathrm{~min})$. Interviews were transcribed.

\subsection{Data processing}

Data processing involved four steps: (a) identifying meaningful units; (b) categorizing the content of information elements held by each athlete and his/her coach at each point in time; (c) categorizing the content of compatible information elements between the athlete and his/her coach; and (d) identifying the nature of information elements held by each athlete and his/her coach at each point in time, namely the genotype and phenotype schemata.

Firstly, as in Macquet's (2013) method, two researchers used inductive analysis (Corbin and Strauss, 1990). Each researcher divided the transcripts into meaningful units according to the participant's activated schemata (see Table 1). Each unit contained information elements pertaining to the activated schemata in relation to different parts of the athlete's behavior, focus, feelings, and situation.

Secondly, as in Macquet's (2013) method, meaningful units were synchronized with the video recordings from the training sessions and competition. Researchers did not elicit information elements when the athlete and coach were communicating because, ac cording to the DSA model, communication leads to compatibility (because one accessed to the interpretation of the other one). They also compared the athlete's focus with the coach's feedback on the previous throw or row, to identify whether the athlete had in mind the instructions and feedback given by the coach, when preparing to undertake an action. In contrast to Macquet's (2013) method, researchers then categorized the content of information elements held by: (a) athletes; and (b) coaches, at the same point in time. Each category was identified and its properties described (see Table 1).

Thirdly, as in Macquet's (2013) method, researchers compared synchronized meaningful units of each athlete's and his/her coach's SA in order to categorize the content of information elements that were compatible (see Table 1). As comparing synchronized meaningful units, they checked whether information elements were compatible or different. They were compatible as: (a) the athlete and coach reported on the same information elements (e.g., "I' $m$ tired/she looks tired", Rower 1 and her coach, WTS); and (b) they talked about the same part of behavior and situation, and the one described what happened and the other one explained possible causes of what happened at a specific time (e.g., "I felt the hammer dropped on the right in the first turn and stayed there a bit"/"his rotation lacks speed in the first turn because his right support is a little weak" HT1 and his coach). They were different as: (a) the coach and athlete reported on different information about the same situation, part of behavior and performance; (b) they reported on the same point differently (e.g., "I think I'm going to be stiff during the training session"/"I believe she's not going to be stiff", Rower 1 and her coach, WTS); and (c) only one participant reported information elements regarding his/her SA at a specific time (e.g., "I feel the throw distance is correct"/the coach did not report on HT2's performance).

Fourthly, to supplement Macquet's (2013) method, researchers analyzed information elements held by the coach and those held by athlete, in order to identify whether information elements pertained to genotypes and phenotypes schemata. Information elements pertained to phenotype schemata as the participant solely described athlete's behavior, thought, feeling, focus, and situation (e.g., "The hammer hit the soil in the second turn", HT3 PCTS). Information elements pertained to a comparison of the phenotype with genotype schemata as the participant compared the put/ behavior just being done to that was expected to be done to perform well, regarding their own "schema-based theory" of how to throw a hammer and to row efficiently. In other terms, the participant activated knowledge in relation to the behavior just

Table 1

Examples of meaningful units, content of information elements, compatibility of information elements, and nature of compatible information elements.

\begin{tabular}{|c|c|c|c|c|c|}
\hline \multicolumn{2}{|l|}{ Meaningful units } & \multirow[t]{2}{*}{$\begin{array}{l}\text { Content of information } \\
\text { elements }\end{array}$} & \multirow{2}{*}{$\begin{array}{l}\text { Compatible } \\
\text { information } \\
\text { elements }\end{array}$} & \multicolumn{2}{|c|}{$\begin{array}{l}\text { Nature of compatible } \\
\text { information elements }\end{array}$} \\
\hline Athlete & Coach & & & Athlete's & Coach's \\
\hline $\begin{array}{l}\text { "I felt the hammer dropped on the right } \\
\text { in the first turn and stayed there } \\
\text { abit." HT2, PCTS }\end{array}$ & $\begin{array}{l}\text { "His rotation lacks speed in the first turn } \\
\text { because his right support is a little weak." }\end{array}$ & Technical elements & Compatible & Phenotype & $\begin{array}{l}\text { Comparison between } \\
\text { phenotype and genotype }\end{array}$ \\
\hline $\begin{array}{l}\text { "The first two turns are better because } \\
\text { the radius is higher."HT1, WTS }\end{array}$ & $\begin{array}{l}\text { "The final is excellent because he increased } \\
\text { the hammer speed in the course of the four } \\
\text { turns." }\end{array}$ & Technical elements & Different & $\begin{array}{l}\text { Comparison } \\
\text { between } \\
\text { phenotype } \\
\text { and genotype }\end{array}$ & $\begin{array}{l}\text { Comparison between } \\
\text { phenotype and genotype }\end{array}$ \\
\hline $\begin{array}{l}\text { "I'm doing this difficult drill. I feel more } \\
\text { confident." R2, WTS }\end{array}$ & $\begin{array}{l}\text { "He's now better at the end of this drill. } \\
\text { I think he's more confident." }\end{array}$ & $\begin{array}{l}\text { Athlete's } \\
\text { psychological } \\
\text { states }\end{array}$ & Compatible & Phenotype & Phenotype \\
\hline "I'm tired." R1, WTS & "She looks tired." & $\begin{array}{l}\text { Organization and } \\
\text { safety }\end{array}$ & Compatible & Phenotype & Phenotype \\
\hline "The put is out the throw sector." HT4, C & $\begin{array}{l}\text { "It's a good put, but it's out of the throw } \\
\text { sector." }\end{array}$ & Performance & Compatible & Phenotype & Phenotype \\
\hline $\begin{array}{l}\text { "It's a first throw; it's bad. It's a little weak } \\
\text { at the beginning of the session; then the } \\
\text { throws become better and better." HT1, } \\
\text { WTS }\end{array}$ & $\begin{array}{l}\text { "It's his first throw. There is nothing to } \\
\text { say. The throws are getting better and } \\
\text { better since the beginning of the training } \\
\text { session" }\end{array}$ & Athlete's experience & Compatible & $\begin{array}{l}\text { Comparison } \\
\text { between } \\
\text { phenotype } \\
\text { and genotype }\end{array}$ & $\begin{array}{l}\text { Comparison between } \\
\text { phenotype and genotype }\end{array}$ \\
\hline
\end{tabular}

Note: WTS = Winter Training Session, C = Competition, PCTS= Post-Competition Training Session, HT1 =Hammer Thrower, HT2 = Hammer Thrower 2 , HT3 = Hammer Thrower 3, HT4 = Hammer Thrower 4, R1 = Rower 1, R2 = Rower 2. 
being done and the ideal/expected behavior in order to know whether behavior just being done fitted with ideal/expected behavior, and explain possible cause of athlete's behavior and hammer/skiff move (e.g., "his rotation lacks speed in the first turn because his right support is a little weak", coach of HT1, PCTS; see also Table 1). Activated knowledge could be explicit (e.g., previous example) and tacit (e.g., "her leg flexion is correct" coach of HT4, PCTS). Due to the way we conducted the interviews (i.e., report on specific situations and behaviors and avoid general descriptions on how to perform well), we did not expect to identify genotype schemata solely.

After each step, researchers compared their results and discussed any initial disagreement until consensus was reached. The reliability of the coding procedure was assessed with Bellack's agreement rate (Von Someren et al., 1994). The initial agreement rate was between $85.31 \%$ and $87.71 \%$ depending on the data processing steps. Interview transcripts were divided into 898 meaningful units for athletes and 653 for coaches.

\section{Results}

Results are presented in three parts: (a) content of information elements pertaining to SA and held by athletes and those held by coaches; (b) content of compatible information elements between each athlete and his/her coach; and (b) nature of information elements held by athlete and those held by coaches.

\subsection{Content of information elements held by athletes and coaches}

Analysis of the content of information elements pertaining to the coach's and athlete's SA indicated five categories of information elements: (a) technical elements; (b) athlete's psychological states; (c) organization and safety; (d) performance; and (e) athlete's experience (see Table 1).

Technical elements referred to information about the spatial and temporal form of the action the athlete had just completed and was about to complete, and hammer/skiff move. For example, HT1 said: "I felt my legs were flexed more than in the previous put", and his coach said: "the leg flexion is correct" (WTS).

Athlete's psychological states were related to his/her motivation, confidence, and mood during the action. For example, R2 said: "I'm now doing this difficult drill. I feel more confident", and his coach said: "he's now better at the end of this drill. I think that he's more confident" (PCTS).

Organization and safety concerned the current training session and competition program, the circle surface state (i.e., neither slippery nor rough) or river state (e.g., eddies, debris, wind), and the athlete's freshness during the action. For example, R1 said: "the barge is making waves" and her coach said: "the water is moving because of the barge" (WTS).

Performance referred to the throw length or skiff speed and stroke rate. For example, HT3 said: "It's 70.23 meters" (competition).

Athlete's experience related to previous events and associated knowledge that the athlete and coach shared about the athlete. For example, HT1 said "I have a drink to avoid cramp around the 20th throw" and his coach said: "He drinks because he gets cramp more often than other athletes" (PCTS).

Results showed that technical elements were the most frequently identified category among athletes and coaches (see Fig. 1); they were more frequently mentioned by coaches than athletes, with the exception of HT3 in competition (see Table 2); they were also more frequently mentioned by coaches and athletes in training sessions than competition and in PCTS than WTS; furthermore, they were more frequently mentioned by coaches and athletes in hammer throwing than in rowing. Psychological states were mainly mentioned in competition; they were mentioned more by athletes than coaches. Organization and safety was more frequently mentioned by athletes than coaches, across all sessions, with the exception of HT2 and his coach in competition; it was more frequently reported in rowing than hammer throwing. Performance was more frequently mentioned by athletes than coaches, across all sessions, with the exception of HT1 and HT3 and her coach in WTS; it was more frequently mentioned in competition than training sessions for all athletes and their coach, with the exception of coach of HT2. Athlete's experience was seldom mentioned by the athletes and their coaches across all sessions.

\subsection{Content of compatible information elements held by the athletes and coaches}

The comparison between the information elements reported by the athletes and their coach at each point in time showed whether information elements were compatible or different. They were considered compatible if their meaning was similar or the same (e.g., HT2 said: "I transferred my weight to the right support too late" and his coach said: "he's not early enough on his right support", competition).

They were considered different if their meaning was different, i.e., when: (a) the athlete and coach commented upon different parts of the behavior and situation or only one of them commented on it (e.g., HT3 said: "I felt the hammer hitting the soil on the third turn", and her coach said: "her placement on the first two turns is

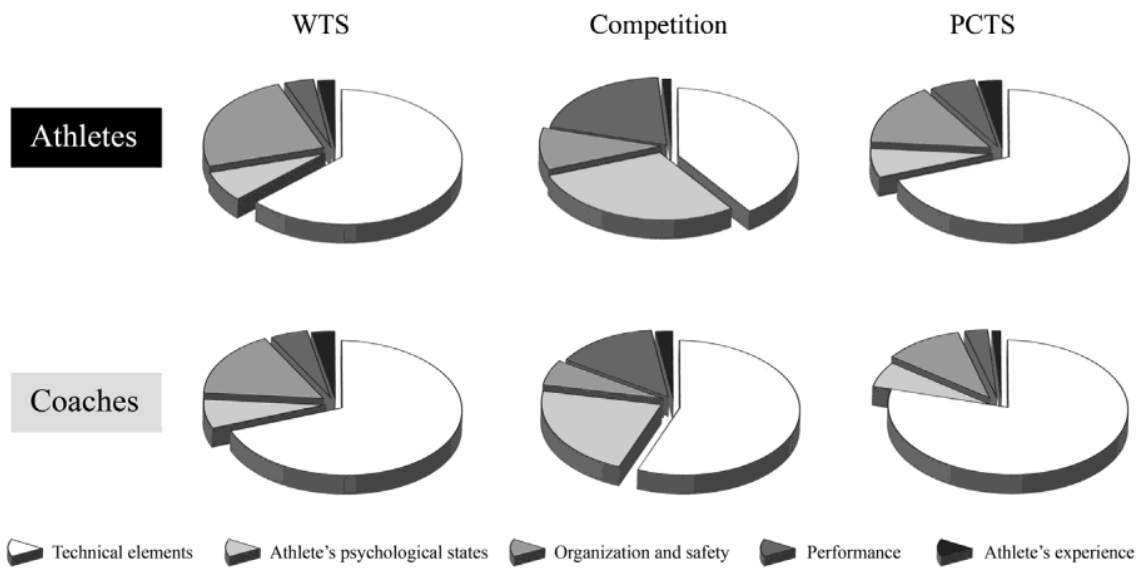

Fig. 1. Distribution of information elements according to session and athletes' and coaches' SA. 
fairly good", WTS); or (b) they commented on the same part of the behavior and situation differently (e.g., R1 said: "I'm feeling stiff" and her coach said: "I don't think she's going to be stiff during the training session" WTS).

Analysis of compatible information elements between the coach's and athlete's SA highlighted differences in the frequency of categories between training sessions and competitions (see Fig. 2). The most frequent category overall practice conditions referred to technical elements. The athlete and his/her coach more frequently reported on similar technical elements during training sessions than competitions, and in PCTS than WTS, with the exception HT1 and his coach (see Table 3). In comparison to other categories of information elements, technical elements were more frequently similar between the athlete and his/her coach in hammer throwing than rowing. Psychological states were more frequently similar between the coach and his athlete in competition than training sessions. Organization and safety were seldom similar between the hammer thrower and his/her coach in training session and competition whereas they were frequently similar between the rower and his/her coach. Performance was more frequently similar in competition than training session, with the exception of HT2 and his coach. Athlete's experience was seldom similar between each athlete and his/her coach.

\subsection{Nature of the schemata containing information elements held by each athlete and his/her coach at each point in time}

The analysis of the nature the schemata containing information elements held by the athlete and those held by his/her coach at each point in time showed whether they reported on the phenotype schemata solely whether compared the phenotype with genotype schemata. The phenotype schemata was concerned with the athlete's behavior, feeling, focus, thought, performance, and situation (e.g., "the throw is $76.5 \mathrm{~m}$ long", HT2, Competition). Comparison between the phenotype and genotype schemata aimed to explain possible causes of athlete's behavior and situation (e.g., "she gets up on her legs because she's not anticipating and is keeping her left foot closed" HT3's Coach, WTS; "the first two turns are better because the radius is longer", HT1, WTS) and to assess whether the behavior being completed fitted the ideal/expected behavior to be completed (e.g., "the leg flexion is correct", HT3, WTS).

Analysis of the nature of information elements showed similarities and differences between the athletes and coaches (see Fig. 3). Information elements held by the athletes and coaches more frequently referred to the phenotype schemata solely, rather than a comparison between the phenotype and genotype schemata. In other words, they more frequently just described what happened,

Table 2

Frequency of information elements and their ratio according to session, and athlete's and coach's SA.

\begin{tabular}{|c|c|c|c|c|c|c|}
\hline $\begin{array}{l}\text { Session and athlete's and } \\
\text { coach's SA }\end{array}$ & $\begin{array}{l}\text { Frequency of information elements } \\
\text { in relation to meaningful units }\end{array}$ & $\begin{array}{l}\text { Technical } \\
\text { elements }\end{array}$ & $\begin{array}{l}\text { Athlete's psychological } \\
\text { states }\end{array}$ & $\begin{array}{l}\text { Organization } \\
\text { and safety }\end{array}$ & Performance & $\begin{array}{l}\text { Athlete's } \\
\text { experience }\end{array}$ \\
\hline \multicolumn{7}{|l|}{ Athlete's SA } \\
\hline \multicolumn{7}{|l|}{ WTS } \\
\hline HT1 & 82 & .64 & 0 & .34 & .01 & .01 \\
\hline HT2 & 86 & .74 & .02 & .12 & .09 & .02 \\
\hline HT3 & 106 & .67 & .15 & .07 & .07 & .04 \\
\hline $\mathrm{R} 1$ & 99 & .45 & .13 & .42 & 0 & 0 \\
\hline Total & 373 & .63 & .07 & .24 & .04 & .02 \\
\hline \multicolumn{7}{|l|}{$\mathrm{C}$} \\
\hline HT1 & 58 & .51 & .15 & .07 & .24 & .03 \\
\hline HT2 & 108 & .38 & .36 & .11 & .15 & 0 \\
\hline HT3 & 63 & .25 & .37 & .19 & .19 & 0 \\
\hline HT4 & 56 & .46 & .29 & .04 & .21 & 0 \\
\hline Total & 285 & .40 & .29 & .10 & .20 & .01 \\
\hline \multicolumn{7}{|l|}{ PCTS } \\
\hline HT1 & 53 & .68 & .04 & .19 & .05 & .04 \\
\hline HT2 & 55 & .87 & .04 & .04 & .05 & 0 \\
\hline HT4 & 47 & .66 & .11 & .06 & .11 & .06 \\
\hline $\mathrm{R} 2$ & 85 & .54 & .08 & .33 & .04 & .01 \\
\hline Total & 240 & .69 & 07 & .15 & .06 & .03 \\
\hline Total & 898 & .55 & .16 & .17 & .10 & .02 \\
\hline \multicolumn{7}{|l|}{ Coach's SA } \\
\hline \multicolumn{7}{|l|}{ WTS } \\
\hline $\mathrm{CO}$ of HT1 & 46 & .76 & .02 & .17 & 0 & .05 \\
\hline $\mathrm{CO}$ of $\mathrm{HT} 2$ & 61 & .74 & .05 & .08 & .10 & .03 \\
\hline $\mathrm{CO}$ of HT3 & 64 & .72 & .12 & .03 & .11 & .02 \\
\hline $\mathrm{CO}$ of $\mathrm{R} 1$ & 81 & .54 & .10 & .36 & 0 & 0 \\
\hline Total & 252 & .69 & .07 & .16 & .05 & .03 \\
\hline \multicolumn{7}{|l|}{$\mathrm{C}$} \\
\hline $\mathrm{CO}$ of HT1 & 40 & .70 & .10 & .05 & .13 & .02 \\
\hline $\mathrm{CO}$ of HT2 & 83 & .58 & .23 & .12 & .07 & 0 \\
\hline $\mathrm{CO}$ of HT3 & 50 & .40 & .36 & .06 & .18 & 0 \\
\hline CO of HT4 & 40 & .57 & .20 & 0 & .18 & .05 \\
\hline Total & 213 & .56 & .22 & .06 & .14 & .02 \\
\hline \multicolumn{7}{|l|}{ PCTS } \\
\hline $\mathrm{CO}$ of $\mathrm{HT} 1$ & 30 & .88 & .03 & .06 & 0 & .03 \\
\hline $\mathrm{CO}$ of HT2 & 42 & .93 & 0 & .07 & 0 & 0 \\
\hline $\mathrm{CO}$ of HT4 & 31 & .80 & .10 & 0 & .10 & 0 \\
\hline $\mathrm{CO}$ of $\mathrm{R} 2$ & 85 & .53 & .10 & .32 & .04 & .01 \\
\hline Total & 188 & .80 & .10 & 0 & .10 & 0 \\
\hline Total & 653 & .68 & .12 & .11 & .07 & .02 \\
\hline
\end{tabular}

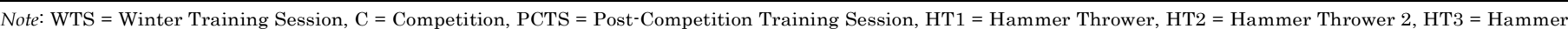

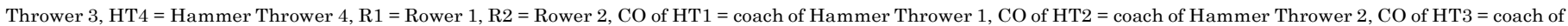
Hammer Thrower 3, CO of HT4 = coach of Hammer Thrower 4, CO of R1 = coach of Rower 1, CO of R2= coach of Rower 2. 


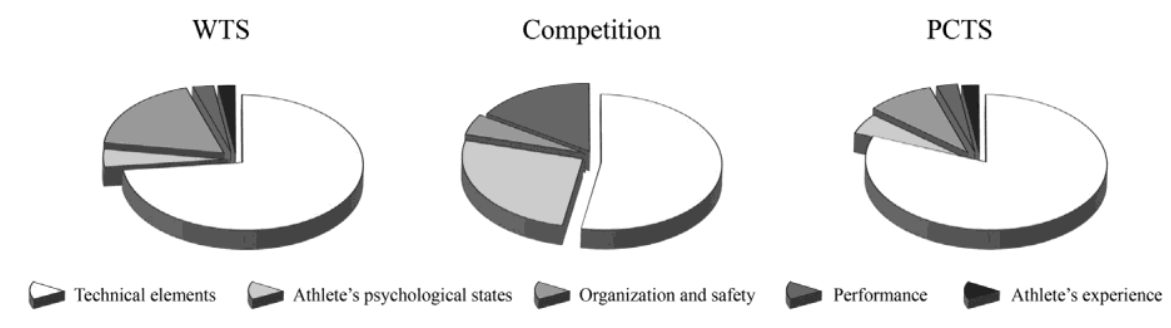

Fig. 2. Distribution of compatible information elements between the athletes' and coaches' SA according to session.

what the athlete focused on, thought, and felt, than they explained possible causes of athlete's behavior and situation, and whether the athlete's behavior and situation fitted ideal/expected behavior and situation. However, in comparison to athletes, coaches more frequently compared the phenotype with genotype schemata (see also Table 4).

\section{Discussion}

These results are discussed in relation to two sets of findings related to coaching and collaborative work. The first concerns the influence of the environment on the construction of the "picture" of the situation. The second concerns the influence of the individual on the construction of the "picture".

\subsection{Evidence of SA directed externally towards the environment}

As the Distributed Situation Awareness model predicts, information elements were related to the development of the situation over time. Results showed five categories of information elements: (a) throw technical elements; (b) athlete's psychological states; (c) organization and safety; (d) performance; and (e) athlete's experience. The present results suggest that athletes' and coaches' SA indicated a "picture" of the situation that was externally directed towards the environment and athlete, and adhered to the task goals and performance criteria, and is consistent with previous works on SA (e.g., Smith and Hancock, 1994) and DSA (e.g., Stanton et al., 2006).
Results showed that technical elements were the category most frequently reported and compatible between the athlete's and coach's SA. They highlighted the weight of technique in building up the "picture". Elite athletes learn to improve their technique in order to achieve high-level performance. This learning consisted of adjustments to specific parts of behavior (e.g., increased leg flexion). Results suggest that SA was governed by a combination of the action that had been completed/was being undertaken, what was required to be achieved and what had been achieved in the previous action. Results also suggest that SA is mainly governed by the learning dimension. They are inconsistent with previous research on mutual understanding during training sessions within the coach-athlete dyad (Lorimer and Jowett, 2009a, 2009b, 2010, 2011). Previous research showed that mutual understanding during training sessions was largely based on the sharing of psychological states with another person (i.e., feelings and thoughts). In the present results, athletes and coaches seldom mentioned athletes' psychological states during training sessions; they were more likely to comment on them during competition.

Information elements concerning technical elements were more frequently reported and compatible in training sessions than competition, and in PCTS rather than WTS. In other words, athletes and coaches focused on technique to prepare for competitions and adjusted their preparation to what had happened in competition and previous training sessions, which is consistent with previous research concerning coaching (Macquet, 2010).

In competition, although coaches and athletes mainly focused on technical elements, they also centered on athletes' psychological states and performance. Moreover, athletes more frequently

Table 3

Frequency of compatible information elements and their ratio according to session, and athlete's and coach's SA.

\begin{tabular}{|c|c|c|c|c|c|c|}
\hline $\begin{array}{l}\text { Session and athlete's } \\
\text { and coach's SA }\end{array}$ & $\begin{array}{l}\text { Frequency of } \\
\text { information elements }\end{array}$ & $\begin{array}{l}\text { Technical } \\
\text { elements }\end{array}$ & $\begin{array}{l}\text { Athlete's psychological } \\
\text { states }\end{array}$ & $\begin{array}{l}\text { Organization } \\
\text { and safety }\end{array}$ & Performance & Athlete's experience \\
\hline \multicolumn{7}{|l|}{ WTS } \\
\hline HT1C & 50 & .86 & 0 & .10 & 0 & .04 \\
\hline $\mathrm{HT} 2 \mathrm{C}$ & 51 & .78 & .04 & .08 & .08 & .02 \\
\hline HT3C & 48 & .82 & .06 & .04 & .06 & .02 \\
\hline $\mathrm{R} 1 \mathrm{C}$ & 63 & .44 & .08 & .48 & 0 & 0 \\
\hline Total & 212 & .73 & .04 & .18 & .03 & .02 \\
\hline \multicolumn{7}{|l|}{ C } \\
\hline HT1C & 28 & .68 & .11 & .07 & .14 & 0 \\
\hline $\mathrm{HT} 2 \mathrm{C}$ & 49 & .61 & .31 & .06 & .02 & 0 \\
\hline HT3C & 36 & .36 & .39 & .08 & .17 & 0 \\
\hline HT4C & 40 & .45 & .25 & 0 & .30 & 0 \\
\hline Total & 153 & .53 & .26 & .05 & .16 & 0 \\
\hline \multicolumn{7}{|l|}{ PCTS } \\
\hline HT1C & 28 & .75 & .04 & .07 & .07 & .07 \\
\hline HT2C & 33 & .97 & 0 & .03 & 0 & 0 \\
\hline HT4C & 18 & 1 & 0 & 0 & 0 & 0 \\
\hline $\mathrm{R} 2 \mathrm{C}$ & 59 & .53 & .15 & .27 & 5 & 0 \\
\hline Total & 138 & .81 & .05 & .09 & .03 & .02 \\
\hline Total & 503 & .66 & 12 & .14 & .07 & .01 \\
\hline
\end{tabular}

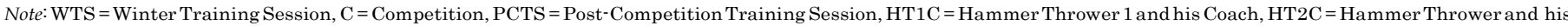
Coach, HT3C = Hammer Thrower 3 and her Coach, HT4C = Hammer Thrower 4 and her Coach, R1C = Rower 1 and her Coach, R2C $=$ Rower 2 and his Coach. 
WTS
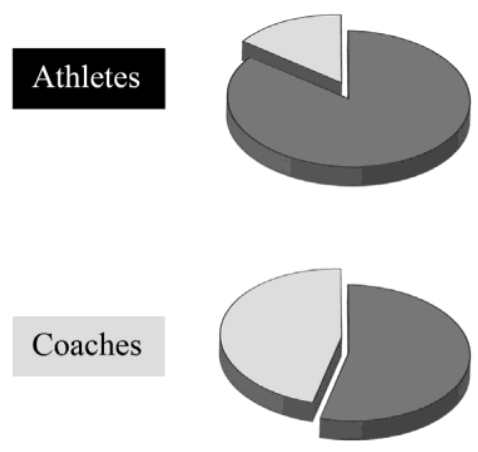

Comparison with phenotype and genotype schemata
Competition
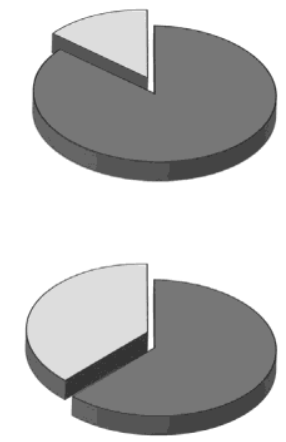

Phenotype schemata

Fig. 3. Distribution of phenotype schemata and comparison with phenotype and genotype schemata according to sessions, and athletes' and coaches' SA.

mentioned them than coaches. Competition is characterized by uncertainty of outcome and high stakes. Uncertainty and high stakes for athletes affect motivation, stress, self-confidence, and athletes' behaviors (e.g., Wilson and Richards, 2011). This suggests that SA depends on the athlete and coach adaptation to the situation's changing external conditions. It also suggests greater coach empathy towards athletes during competition than training sessions. In competition the coach took into account changes in athletes' psychological states in order to help athlete to improve performance. Analysis of the relationships between DSA and performance would be a worthwhile avenue for future research.

Information elements relating to organization and safety were more frequently reported and compatible in rowing than in hammer throwing. This suggests that SA depends on the context and conditions in which a sport is practiced. In rowing, conditions relate to wind, current, sense of navigation (looking forward for the coach and behind for the rower) and other boats navigating on the river; these were not as stable as in hammer throwing. These conditions influenced athletes, who had to take them into account in order to navigate safely and effectively. These results suggest that SA requirements differ according to sport and the conditions in which it is practiced (e.g., rowing on a river or a rowing machine). Although hammer throwing and rowing are both technical sports and correct technique is necessary for good performance, the conditions in which they are practiced might influence SA requirements. Analysis of SA requirements across sports would seem a worthwhile avenue for future research.

\subsection{Evidence of SA directed internally towards the individual}

As the Distributed Situation Awareness model predicts (e.g., Stanton et al., 2006), and schema theory would predict (Plant and Stanton, 2013), the athletes and coaches possessed unique but compatible portions of awareness. They did not always understand the elements of the situation in exactly the same way. They might have had different pieces of information, or made different sense of them depending on their role, task, and experience.

Results showed that the athletes commented more frequently than the coaches on behavior and situation (see the frequency of information elements in relation to meaningful units in Table 2). For example, the hammer throwers commented more on organization and safety (e.g., cleaning their shoes before entering the circle) when preparing to throw than their coach. Results showed that, on the one hand, coaches mainly focused on technical elements during training sessions and competitions, and athletes' psychological states and performance during competitions; on the other hand, although athletes mainly focused on technical elements during training sessions and competitions, they also centered on their psychological states, performance and organization and safety in practice conditions. These results suggest that the coach's role within the team consists of observing and advising the athlete on improving his/her technique and coping with difficult situations to maximize performance, whereas the athlete's role consists of carrying out actions using a specific technique and, at the same time, taking into account his/her psychological states, organization and safety, performance, and making sense of all the parameters. Coaches train several athletes over a long period and thus have wide experience whereas the athlete trains him/herself and has developed "self-centered experience". These different roles and experience seem to govern SA development and the way the athlete and coach understand a situation differently.

They might also explain how some information elements were different between the athlete and coach and some others were compatible. Results suggest that coach's and athlete's SA is considered as a whole combined experience. The connections people experience (i.e., data in the frame) are different. So, whilst they may share data, the connections of data-in-the-frame (i.e., schema) are different.

From a practical perspective, it seems important to ensure that the coach's and athlete's portions of SA are compatible. This should help them to get compatible views of the situation. Compatible SA should allow them to focus on common elements of performance, moving to cognitive joint perspective and being on the same common ground (Clark, 1996). This compatibility could be improved by transaction (i.e., exchange of information between the coach and athlete) according to the DSA model. Exploring transactions would be a worthwhile avenue for future research in sports and other contexts.

Finally, results showed the nature of information elements held by the coaches and athletes, namely the phenotype and genotype schemata. Results highlighted that coaches more frequently compared the phenotype with genotype schemata than athletes, meaning they more frequently explained the possible causes of athlete's behavior and situation than athletes. This suggests that the coaches and athletes used their own schemata to describe and make sense of athlete's behavior, feelings, thoughts and situation. They used different schemata (i.e., phenotype and genotype) because of their different experiences and roles within the team. The athlete who was expected to undertake a particular action, rather used phenotype schemata to describe what he/she did and 
Table 4

Frequency of phenotype schemata and comparison with phenotype and genotype schemata and their ratio according to session and athlete's and coach's SA.

\begin{tabular}{|c|c|c|c|}
\hline $\begin{array}{l}\text { Session and athlete's, and coach's phenotype schemata } \\
\text { and comparison with phenotype and genotype schemata }\end{array}$ & $\begin{array}{l}\text { Frequencies of phenotype schemata and } \\
\text { comparison with phenotype and genotype } \\
\text { schemata }\end{array}$ & Phenotypes & $\begin{array}{l}\text { Comparison with } \\
\text { phenotype and } \\
\text { genotype schemata }\end{array}$ \\
\hline \multicolumn{4}{|l|}{ Athlete's SA } \\
\hline \multicolumn{4}{|l|}{ WTS } \\
\hline HT1 & 82 & .84 & .16 \\
\hline HT2 & 86 & .80 & .20 \\
\hline HT3 & 106 & .77 & .23 \\
\hline $\mathrm{R} 1$ & 99 & .95 & .05 \\
\hline Total & 373 & .85 & .15 \\
\hline \multicolumn{4}{|l|}{ C } \\
\hline HT1 & 58 & .83 & .17 \\
\hline HT2 & 108 & .88 & .12 \\
\hline HT3 & 63 & .89 & .11 \\
\hline HT4 & 56 & .84 & .16 \\
\hline Total & 285 & .86 & .14 \\
\hline \multicolumn{4}{|l|}{ PCTS } \\
\hline HT1 & 53 & .87 & .13 \\
\hline HT2 & 55 & .78 & .22 \\
\hline HT4 & 47 & .89 & .11 \\
\hline $\mathrm{R} 2$ & 85 & .94 & .06 \\
\hline Total & 240 & .87 & .13 \\
\hline Total & 898 & .86 & .14 \\
\hline \multicolumn{4}{|l|}{ Coach's SA } \\
\hline \multicolumn{4}{|l|}{ WTS } \\
\hline HT1 & 46 & .46 & .54 \\
\hline HT2 & 61 & .47 & .53 \\
\hline HT3 & 64 & .52 & .48 \\
\hline $\mathrm{R} 1$ & 81 & .70 & .30 \\
\hline Total & 252 & .54 & .46 \\
\hline \multicolumn{4}{|l|}{$\mathrm{C}$} \\
\hline HT1 & 40 & .58 & .42 \\
\hline HT2 & 83 & .60 & .40 \\
\hline HT3 & 50 & .68 & 32 \\
\hline HT4 & 40 & .63 & .37 \\
\hline Total & 213 & .62 & .38 \\
\hline \multicolumn{4}{|l|}{ PCTS } \\
\hline HT1 & 30 & .57 & .43 \\
\hline HT2 & 42 & .52 & .48 \\
\hline HT4 & 31 & .65 & .35 \\
\hline $\mathrm{R} 2$ & 85 & .81 & .19 \\
\hline Total & 188 & .64 & .36 \\
\hline Total & 653 & .61 & .39 \\
\hline
\end{tabular}

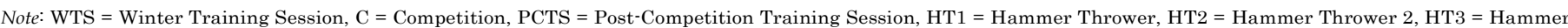

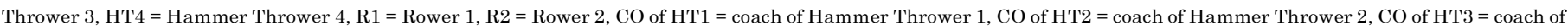
Hammer Thrower 3, CO of HT4 = coach of Hammer Thrower 4, CO of R1 = coach of Rower 1, CO of R2= coach of Rower 2.

felt, whereas the coach who was required to help the athlete achieve a successful outcome, rather compared the phenotype with genotype schemata to explain possible causes of what the athlete did/felt, in order to understand how to maintain or improve athlete's behavior. These results are consistent with the DSA model: partners' roles and experience governed SA and gave them unique but compatible portions of awareness. Limited research has provided evidence of identification of the phenotype and genotype schemata (Stanton et al., 2009), and to our knowledge, no research has provided evidence of differences in the use of phenotype and genotype schemata among team members. The present study, however, showed that $14 \%$ of the athletes' information elements referred to a comparison between the phenotype and genotype schemata, whereas $39 \%$ of the coaches' information elements referred to.

The method developed by Macquet (2013) and supplemented in the present study seems useful for the study of DSA. As a post-event method (Sorensen and Stanton, 2012) it allows comparison of the consistency of athlete's and coach's SA and shows what governs SA within a cognitive joint system. Like the method developed by the DSA model, it allows modeling of system awareness and information elements underlying SA. In contrast to the method developed by the DSA model, however, it provides the frequency of categories of information elements (macro information elements) held by each participant and those which are compatible between the coach's and athlete's SA in different situations (training sessions and competitions). It also highlights the nature of information elements, namely the genotype and phenotype schemata held by each participant depending on his/her role, experience, and competencies. In contrast to the DSA method and to be comprehensible by non-experts, it does not describe the micro-information elements. However, even though we did not describe this, it offers the opportunity to categorize micro information elements. For example, different kinds of technical elements such as speed, rhythm, and amplitude could be categorized. These different categories (i.e., macro and micro information elements) might be useful in highlighting what coaches and athletes focus on as they work on technique.

Some limitations of this study should be noted. Firstly, the method has been developed for small samples. Its use to study larger samples, including sport, surgery, and military teams would be a worthwhile avenue for future research on collaborative systems. Secondly, it did not feature non-expert athletes and short coacheathlete relationships. Thus, the extent to which coach's and 
non-expert athlete's SA with different relationship durations, are similar or identical is unknown. Thirdly, the study featured only two technical sports (i.e., hammer throwing and rowing) and it could be argued that the results presented here are not representative of other sports, athletes and coaches. It would be of interest to study DSA with coaches and athletes from different levels, relationship durations, and sports (i.e., 'technical sports' and 'strategic sports'), and DSA with teammates in team sports.

\section{Conclusion}

Coaches and athletes were shown to possess some common ground, but also some important differences within their SA. The awareness was directed externally towards the environment and internally, towards the individual, depending on his/her role. The investigation showed that the schemata used to 'frame' the information elements were different, but compatible, between athlete and coach. The continuing study of DSA in domains such as hammer throwing and rowing will extend our understanding of collaborative systems in sports as well as in other domains characterized by collaboration and cooperation under conditions of uncertainty and complexity.

\section{Acknowledgments}

This study was supported by a grant from the French National Institute of Sports, Expertise and Performance (INSEP), French Ministry of Sports, and French Federation of Track and Field (FFA). The authors are grateful to the athletes and their coaches for their participation in this study and to Etienne Barraux, for his participation in the video recording of the rowers and his help in the data processing.

\section{References}

Anderson, R.C., 1977. The notion of schemata and the educational enterprise. In: Anderson, R.C., Spiro, R.J., Monatague, W.E. (Eds.), Schooling at the Acquisition of Knowledge. Lawrence Erlbaum, Hillsdale, NJ, pp. 415e431.

Annett, J., Stanton, N.A., 2000. Editorial team work e a problem for ergonomics? Ergonomics 43 (8), 1045e1051.

Bartlet, F.C., 1932. Remembering: a Study in Experimental and Social Psychology. Cambridge University Press, Cambridge.

Bedny, G., Meister, D., 1999. Theory of activity and situation awareness. Int. J. Cogn. Ergon. 3, 63e72.

Clark, H.H., 1996. Using Language. Cambridge University Press, Cambridge, UK.

Corbin, J., Strauss, A., 1990. Basics of Qualitative Research: Grounded Theory. Procedures and Techniques. Sage, Newbury Park, CA.

Endsley, M.R., 1995. Towards a theory of situation awareness in dynamic systems. Hum. Factors 37, 32e64.

Ericsson, K.A., Delaney, P., Weaver, G., Mahadevan, R., 2004. Uncovering the structure of a memorist's superior "basic" memory capacity. Cognit. Psychol. 49, $191 \mathrm{e} 237$.

Hanton, S., Cropley, B., Lee, S., 2009. Reflective practice, experience, and the interpretation of anxiety symptoms. J. Sports Sci. 27, 517e533.

Hollnagel, E., 1998. Cognitive Reliability and Error Analysis Method. Elsevier Science, Oxford.

Hollnagel, E., 1993. Human Reliability and Error Analysis Method. Academic Press, London.

Hutchins, E., 1995. How a cockpit remembers its speeds. Cogn. Sci. 19, 265e288.
James, N., Patrick, J., 2004. The role of situation awareness in sport. In: Banbury, S., Tremblay, S. (Eds.), A Cognitive Approach to Situation Awareness: Theory and Application. Ashgate, Aldershot, UK, pp. 297e316.

Johnson, J.G., Raab, M., 2003. Take the first: option-generation and resulting choices. Organ. Behav. Hum. Decis. Process. 91, $215 \mathrm{e} 229$.

Klein, G., Wiggins, S., Dominguez, C.O., 2010. Team sensemaking. Theor. Issues in Ergon. Sci. 11 (4), 304e320.

Lorimer, R., Jowett, S., 2011. Empathic accuracy, shared focus, and the assumptions of similarity made by coaches and athletes. Int. J. Sport Psychol. 42, 40e54.

Lorimer, R., Jowett, S., 2010. Feedback of information in the empathic accuracy of sport coaches. Psychol. Sport Exer. 11, 12e17.

Lorimer, R., Jowett, S., 2009a. Empathic accuracy meta-perspective, and satisfaction in the coach-athlete relationship. J. Appl. Sport Psychol. 21, $201 e 212$.

Lorimer, R., Jowett, S., 2009b. Empathic accuracy in coach-athlete dyads who participate in team and individual sports. Psychol. Sport Exer. 10, 152e158.

Macquet, A.-C., 2013. Getting on the same page: a method to study the consistency of coaches' and athletes' situation understanding during training sessions and competitions. The Sport Psychol. 27, 292e295.

Macquet, A.-C., 2010. Time management in the context of elite sport training. The Sport Psychol. 24, 194e210.

Macquet, A.-C., 2009. Recognition within the decision-making process: a case study of expert volleyball players. J. Appl. Sport Psychol. 21, 64e79.

Macquet, A.-C., Eccles, D.W., Barraux, E., 2012. What makes an orienteer an expert? A case study of a highly elite orienteer's concerns in the course of competition. J. Sports Sci. 30, 91e99.

Macquet, A.-C., Fleurance, P., 2007. Naturalistic decision-making in expert badminton players. Ergonomics 50, 1433e1445.

Macquet, A.-C., Kragba, K., 2014. What makes basketball players continue with the planned play or change it? Cogn. Technol. Work (in press).

Neisser, U., 1976. Cognition and Reality: Principles and Implications of Cognitive Psychology. Freeman, San Francisco.

Nieuwenhuys, A., Hanin, Y.L., Bakker, F.C., 2008. Performance-related experiences and coping during races: a case study of an elite sailor. Psychol. Sport Exer. 9, $61 e 76$.

Norman, D.A., 1981. Categorization of action slips. Psychol. Rev, 88, 1e15.

Piaget, J., 1926. The Child's Conception of the World. Harcourt Press, New York.

Plant, K.L., Stanton, N.A., 2013. The explanatory power of Schema Theory: theoretical foundations and future applications in ergonomics. Ergonomics 56 (1), $1 e 15$.

Salas, E., Prince, C., Baker, D.P., Shresta, D.P., 1995. Situation awareness in team performance: implications for measurement and training. Hum. Factors 37, $123 e 136$.

Salmon, P.M., Stanton, N.A., Gibbon, A.C., Jenkins, D.P., Walker, G.H., 2010a. Human Factors Methods and Sports Science. CRC Press, Boca Raton, Fl.

Salmon, P.M., Stanton, N.A., Walker, G.H., Jenkins, D.P., Rafferty, L., 2010b. Is it really better to share? Distributed situation awareness and its implications for collaborative system design. Theor. Issues Ergon. Sci. 11, $58 \mathrm{e} 83$.

Smith, K., Hancock, P.A., 1995. Situation awareness is adaptive, externally-directed consciousness. Hum. Factors 37, 137e148.

Sorensen, L.J., Stanton, N.A., 2012. Should we assess distributed situation awareness before, during or after command and control activity? J. Battlef. Technol. 15 (1), $41 e 48$.

Stanton, N.A., Salmon, P.M., Walker, G.H., Jenkins, D.P., 2010. Is situation awareness all in the mind? Theor. Issues Ergon. Sci. 11, 29e40.

Stanton, N.A., Salmon, P.M., Walker, G.H., Jenkins, D.P., 2009. Genotype and phenotype and their role in distributed situation awareness in collaborative systems. Theor. Issues Ergon. Sci. 10, $43 e 68$.

Stanton, N.A., Stewart, R., Harris, D., Houghton, R.J., Baber, C., McMaster, R., Salmon, P., Hoyle, G., Walker, G., Young, M.S., Linsell, M., Dymott, R., Green, D., 2006. Distributed situation awareness in dynamic systems: theoretical development and application of an ergonomics methodology. Ergonomics 49, 1288e 1311.

Simon, H.A., 1996. The Sciences of Artificial. MIT Press, Cambridge, MA.

Von Someren, M.W., Barnard, Y.F., Sandleberg, J.A.C., 1994. The Think Aloud Method: a Practical Guide to Modelling Cognitive Processes. Academic Press, London.

Wilson, M.R., Richards, H., 2011. Putting it together: skills for pressure performance. In: Collins, D., Burton, A., Richard, H. (Eds.), Performance Psychology. Elsevier, Oxford, UK, pp. 337e360.

Wood, D., 1998. How Children Think and Learn?, second ed. Blackwell, Oxford. 